\title{
Does Hong Kong remain an equivalent jurisdiction for the EU credit rating regime?
}

\author{
Syren Johnstone* \\ Faculty of Law \\ 10/F, Cheng Yu Tung Tower \\ Centennial Campus \\ The University of Hong Kong \\ Pokfulam Road \\ Hong Kong \\ Email: syrenj@hku.hk
}

\begin{abstract}
$^{* *}$
Credit ratings issued by credit rating agencies regulated in Hong Kong are serviceable in the European Union (EU) because Hong Kong is recognized for these purposes as an equivalent jurisdiction. The perimeter of Hong Kong's credit rating regime has recently come under the scrutiny of the Securities and Futures Appeals Tribunal, which has established important boundary lines impacting on the authorization, supervision and enforcement of the credit rating industry in Hong Kong. This article analyzes the case and identifies four elements central to it, namely, the information-based, document-based and act-based perimeters of the Hong Kong regime as well as its primary regulatory objective. It is suggested that the Tribunal's approach to these elements may represent a material departure of Hong Kong's legal and supervisory framework from the regime in the EU that could adversely affect Hong Kong's standing as an equivalent jurisdiction.
\end{abstract}

\footnotetext{
* Adjunct Associate Professor, Faculty of Law, University of Hong Kong; Fellow, Asian Institute of International Financial Law; Solicitor (England \& Wales and Hong Kong, nonpractising); Director, Keel Consulting

** The author would like to thank for their assistance on an earlier draft of this paper Professor Douglas Arner, Paul Lejot, Nigel Davis, Kingsley Ong and Evan Gibson (all of University of Hong Kong), and Antonio Da Roza (Barrister); the views expressed and any errors remain those of the author. This paper is supported by the RGC Theme-based Research Scheme Project: "Enhancing Hong Kong's Future as a Leading International Financial Centre".
} 


\section{Contents}

\section{Abstract}

1. Introduction

3

2. Hong Kong and the Moody's case

2.1 Foundations of the HK regime

2.2 The Report

2.3 The Tribunal's determination

2.4 Import of the Moody's case

3. Assessing the determination 8

3.1 Information-based perimeter - what constitutes a credit rating? Definitions of credit rating Relationship between credit ratings and creditworthiness The Report

The Tribunal's assessment of the Report

Non-ratings that might be regarded as credit ratings

3.2 Document-based perimeter - what else is relevant?

3.3 Act-based perimeter - what acts are regulated?

3.4 Regulatory objective - what is the primary purpose? 


\section{Introduction}

Hong Kong's legal and supervisory framework for the regulatory oversight of credit rating agencies ("CRAs") was introduced on 1 June 2011 (the "HK regime"). ${ }^{1}$ On 28 April 2014 Hong Kong obtained the EU's implementing decision by which it is regarded as an equivalent jurisdiction for EU purposes (the "equivalence decision"). ${ }^{2}$

Since obtaining equivalence, the question of the precise scope of the HK regime has been subject to the scrutiny of the Securities and Futures Commission ("SFC"), the statutory regulator, and the Securities and Futures Appeals Tribunal ("Tribunal"), a statutory body, chaired by a judge, empowered to review specified decisions of the SFC. ${ }^{3}$ The question arose in connection with a report issued by Moody's Investors Service Hong Kong Limited ("Moody's") shortly after the introduction of the HK regime. The report was titled "Red Flags for EmergingMarket Companies: A Focus on China" (the "Report"), and was available to paying subscribers.

Although Moody's is licensed as a CRA in Hong Kong it did not consider the Report to be a credit rating or part of its regulated activities. However, the SFC regarded the issuance of the Report as falling within its regulatory oversight and imposed on Moody's a pecuniary penalty of HK\$23 million for alleged regulatory breaches. Moody's appealed the matter to the Tribunal, which specifically required it to consider the precise scope of the credit rating regulatory regime. The Tribunal, in Moody's Investors Service Hong Kong Limited $v$ Securities and Futures Commission (Application No. 4 of 2014), concurred with the SFC's finding in this regard. ${ }^{4}$

The case appears to be the first, in Hong Kong or internationally, ${ }^{5}$ that has considered what characteristics of published information or opinion are required for that information or opinion to constitute a credit rating for regulatory purposes, and what it is to engage in credit rating services. Because CRAs issue a variety of reports, many of which are accepted by the industry and regulators as business analysis not constituting a credit rating, the case also represents an exploration of which reports issued by a licensed CRA should be treated as falling within the perimeter of its regulated credit rating activities, and which should not be so treated.

It is of particular interest as the implementation of the HK regime closely and explicitly followed the approach taken internationally post 2008 and to ensure consistency with the EU. ${ }^{6}$ Meeting the EU's test of equivalence and/or stringency was a central objective of the HK regime to enable credit ratings issued by CRAs based in Hong Kong to be serviceable in the EU. ${ }^{7}$

\footnotetext{
${ }^{1}$ The new regime became effective on 1 June 2011Securities and Futures Ordinance (Amendment of Schedule 5) Notice, L.N. 28 of 2011

2 The EU's implementing decision of 28 April 2014 pursuant to Article 5(6) of Regulation (EC) No 1060/2009 of the European Parliament. See Official Journal of the European Union, vol 57, 3 May 2014, page 76-78. The decision came into effect on 23 May 2014

${ }^{3}$ Established under SFO, Part XI, the Tribunal is chaired by a judge assisted by two layperson members.

${ }^{4}$ However, the pecuniary penalty was reduced to $\mathrm{HK} \$ 11$ million

${ }^{5}$ Based on searches using Lexis covering Hong Kong, the UK, all EU member states, US Federal courts, Canada and Australia

${ }^{6}$ SFC's "Consultation Paper Concerning the Regulatory Oversight of Credit Rating Agencies", 19 July 2010, para 3 expressly references the G20 Declaration

7 SFC's "Consultation Conclusions Concerning the Regulatory Oversight of Credit Rating Agencies", 29 October 2010, para 4
} 
This article analyzes the Tribunal's determination and considers its relevance to Hong Kong's ongoing status as an equivalent jurisdiction for EU purposes. Section 2 provides an overview of the HK regime and the Moody's case. Section 3 analyzes the determination and identifies four elements central to it, namely, the information-based, document-based and act-based perimeters of the Hong Kong regime as well as its primary regulatory objective. It is suggested that the Tribunal's approach to these four elements may represent a material departure from the CRA regime in the EU that could adversely affect Hong Kong's standing as an equivalent jurisdiction. Section 4 concludes.

\section{Hong Kong and the Moody's case}

\subsection{Foundations of the HK regime}

The development of the HK regime was a direct product of international developments. In the early 2000 's, prompted by high profile corporate collapses, the international community began to look more closely at the role of CRAs in the financial marketplace and whether they should be subject to regulatory oversight. Work undertaken by the Financial Stability Board ("FSB") and the International Organization of Securities Commissions ("IOSCO") led to IOSCO issuing two documents in 2003 concerning the activities of CRAs and the high-level principles that should govern them. ${ }^{8}$ This was followed, in 2004, by IOSCO's "Code of conduct fundamentals for credit rating agencies" ("IOSCO CRA Code"). ${ }^{9}$ However, it was not until the global financial crisis of 2008 that an international consensus was formed, the Group of Twenty ("G20") requiring that "all Credit Rating Agencies whose ratings are used for regulatory purposes should be subject to a regulatory oversight regime. ${ }^{10}$ A number of countries subsequently implemented CRA regimes having regard to the foregoing, in particular, the approach taken in the IOSCO CRA Code.

In September 2009 the European Union ("EU") promulgated Regulation (EC) No $1060 / 2009$ to regulate CRAs (the "EU regime"). Its stated purposes being, inter alia:

"to enhance the integrity, transparency, responsibility, good governance and reliability of credit rating activities ... [and to lay down] conditions for the issuing of credit ratings". ${ }^{11}$

The effect of the EU regime was to establish three gateways that permitted the use of credit ratings in the EU: ratings issued directly under the EU regime; ratings endorsed by CRAs regulated under the EU regime as complying with requirements as stringent as in the $\mathrm{EU}$; and ratings issued under an equivalent regulatory regime.

The HK regime was designed to benefit from the third of these gateways. As a result, there is a high degree of similarity between the HK and EU regimes, albeit having been implemented differently owing to their different legal systems.

\footnotetext{
8 "Report on the activities of credit rating agencies", and "IOSCO Statement Of Principles Regarding The Activities Of Credit Rating Agencies", both issued in September 2003

9 The IOSCO CRA Code is updated from time to time, the current version being dated March 2015, see IOSCO FR05/2015

10 "Declaration: Summit on Financial Markets and the World Economy", and the "The

Global Plan for Recovery and Reform, London" - statements issued by the G20 leaders, 15 November 2008 and 2 April 2009, respectively

${ }^{11}$ Art 1, Regulation (EC) No 1060/2009 of the European Parliament and of the Council of 16 September 2009 on credit rating agencies
} 
The HK regime comprises both statutory and non-statutory components. The statutory part is established by the Securities and Futures Ordinance ("SFO") ${ }^{12}$ and is based around a concept of regulated activities that closely follow the definitions of "credit rating" and "credit rating agency" in Article 3 of the EU regime and which requiring licensing. Detailed conduct regulation is set out in non-statutory regulation that follows Title II of the EU regime, is expressly based on the IOSCO CRA Code, ${ }^{13}$ and adopts the principles established by IOSCO in its "Regulatory Implementation of the Statement of Principles Regarding the Activities of Credit Rating Agencies"14 ("IOSCO CRA Principles").

The European Securities and Markets Authority's ("ESMA") technical advice concluded that "the Hong Kong legal and supervisory framework in respect of CRAs is comparable to that laid down in Regulation (EC) No 1060/2009", ${ }^{15}$ paving the way for the equivalence decision. However, the equivalence decision is not a one-off passport. It is subject to three conditions being satisfied on an ongoing basis, the first of which requires that CRAs:

"must be subject to authorisation or registration and to effective supervision and enforcement on an ongoing basis ... On this basis, it should be considered that CRAs in Hong Kong are subject to authorisation or registration requirements equivalent to those laid down in Regulation (EC) No 1060/2009 and the Hong Kong supervisory and enforcement arrangements applicable to CRAs are effectively applied and enforced. ${ }^{16}$

This condition is central to the concerns of this article because the equivalence decision was made at a time when no statutory body or Court of law had been asked to determine or rule on the precise scope of the HK regime including its statutorily defined terms. However, this changed in March 2016 when the Tribunal issued its determination on Moody's Report.

\subsection{The Report}

The Report comprised a framework in which red flags were assigned to specified companies across a range of corporate governance and accounting risk issues. The framework comprised 20 red flags grouped into five categories that Moody's described as "screens for governance or accounting risks [that] can help identify areas to investigate but cannot serve as mechanisms to rank order credit risk. ${ }^{17}$ The five categories were:

weaknesses in corporate governance;

riskier or more opaque business models;

fast-growing-business strategies;

poorer quality of earnings or cash flow; and

concerns over auditors and quality of financial statements.

The Report describes the system as identifying "warning signs" for the types of companies covered, being 61 Chinese non-financial companies that fall within Moody's ratings horizon as being "high-yield". ${ }^{18}$ Six of the companies that had

\footnotetext{
12 Chapter 571

13 SFC CRA Code, para 2, referring to the IOSCO CRA Code in effect at that time

${ }^{14}$ FR04/11 February 2011

15 Official Journal of the European Union, vol 57, 3 May 2014, page 76

16 Official Journal of the European Union, vol 57, 3 May 2014, page 76-77

${ }_{17}$ Report page 1

${ }^{18}$ Report page 2
} 
triggered between 7 and 12 red flags were identified as "negative outliers"19 and were subject to additional comments as to "what risks these flags are highlighting." ${ }^{20}$

Based on the significant market reaction to the Report, it appeared to be of considerable interest to both equity and debt investors. ${ }^{21}$ The prevailing environment of concern of regulators and investors over governance and accounting standards in Mainland companies, ${ }^{22}$ the targeted nature of the report, the cautionary note of its red flags, and Moody's status in the market, together contributed to this.

Although Moody's is licensed as a CRA it did not consider the report to be a credit rating or part of its licensed CRA activities. In common with the approach taken internationally, the HK regime recognizes the origins of CRAs are historically borne out of business analysis and that modern day CRAs can and do issue research that amounts to business analysis. ${ }^{23}$ Accordingly, the HK regime does not prohibit a CRA from engaging in ancillary services, ${ }^{24}$ and applicable regulations expressly permit it subject to the requirement that it does not create a conflict of interest for its credit rating services. ${ }^{25}$ This reflects the approach in the EU regime. ${ }^{26}$ It may be noted that the Report had been initiated solely by Moody's and that no conflict issue arose in relation to the Report.

\subsection{The Tribunal's determination}

The SFC's disciplinary action against Moody's was based on it treating the issuance of the Report as falling within its regulatory oversight, and Moody's appeal to the Tribunal argued that as a matter of law it did not. It must here be noted that the statutory and non-statutory components of the HK regime must be kept distinct. While the sanctions applied by the SFC arose from alleged breaches of non-statutory codes, the question of whether or not Moody's issuance of the report is subject to the regulatory jurisdiction of the SFC requires an examination of the empowering legislation, the SFO. Moody's appeal therefore required the Tribunal to interpret the statutory provisions of the SFO defining "credit rating" and the extent and scope of "providing credit rating services" (in Hong Kong also known as Type 10 regulated activity).

The introduction of the HK regime being relatively new, there is no judicial precedent on the matter. Nor does there appear to be any judicial ruling internationally that might be of assistance. ${ }^{27}$ With a view to giving effect to the

\footnotetext{
${ }^{19}$ Report pages 14-15 of Appendix 2

${ }^{20}$ Report page 4

${ }^{21}$ Per the Tribunal, "more than half of the issuers red-flagged in the [Moody's] Report had experienced substantial falls. Four of the six issuers identified in the [Moody's] Report as negative outliers suffered the biggest drops" (Moody's Case [37])

22 The Report cites investigations by the SEC and participants in the markets "are looking into potential problems with the quality of financial reporting from publicly listed Chinese companies" (page 2). The Tribunal cites a New York Times article posted 26 May 2011 "The Audacity of Chinese Frauds" (Moody's Case [18])

23 Langohr, op cit page 2

24 The SFC, in line with international practice, rejected the concept that CRAs should be subject to a sole business restriction. See SFC's 29 October 2010 Consultation Conclusions, op cit para 63

${ }^{25}$ Para 30 of the "Code of Conduct for Persons Providing Credit Rating Services", SFC, June 2011 ("SFC CRA Code")

26 EU regime, Recital (6)

27 Searches were conducted using Lexis in Hong Kong, the UK, all EU member states, US Federal courts, Canada and Australia. Two cases of interest for other reasons were identified and these are discussed elsewhere in this paper, namely, Bathurst Regional
} 
intention of the Legislature, the Tribunal undertook a purposive interpretation of the law that took as its focus the regulated activity of providing credit rating services. The core question for its interpretative exercise was:

"[I]n terms of the relevant statutory provisions, did the publication of the [Moody's] Report (of itself) constitute the provision of credit rating services? ... In determining this issue it is important to note that the phrase 'credit ratings' is broadly defined. ${ }^{28}$

Only if the answer to that question were in the positive would the SFC have jurisdiction over Moody's in relation to the Report. If it were in the negative, then the SFC would have no power to impose regulatory penalties in relation to Moody's Report. ${ }^{29}$

Connecting the red flag framework exclusively and particularly to an opinion on creditworthiness is not a straightforward matter. Nowhere in the Report is the red flag framework described as identifying creditworthiness per se. Nor does it indicate that it has any impact on Moody's existing rating opinions. The opening paragraph of the Report describes the red flag framework as "highlight[ing] issues meriting scrutiny to identify possible governance or accounting risks for nonfinancial corporate issuers". Its front page continues that the framework "can help identify areas to investigate but cannot serve as mechanisms to rank order credit risk", and that the red flags "do not represent a change in our rating methodologies." Page 4 of the Report states that the correlation between the number of red flags and creditworthiness is "limited" - some groupings of companies revealing a "lack of correlation", others showing a "degree of correlation".

Nevertheless, the Tribunal determined the Report to be either (1) itself a credit rating or (2) part and parcel of Moody's ratings themselves. ${ }^{30}$ It observed that more flags represented more warning signs of an increased potential credit risk the number of flags reflecting the level of credit risk - and that this suggested greater scrutiny is required by market participants. ${ }^{31}$ Moreover, it determined that red flag framework amounted to a credit rating because it constituted "a well-defined system or mechanism for judging levels of credit risk." ${ }^{32}$ The Tribunal further determined that even if the Report was not itself a credit rating, then it is part and parcel of Moody's ratings because the Report is intended to amplify and supplement, and is "intimately attendant upon", Moody's credit ratings. ${ }^{33}$ Accordingly, it found that the preparation and issuance of the Report fell within the statutory definition of providing credit rating services.

\footnotetext{
Council v Local Government Financial Services Pty Ltd (No 5) 3 of 6 (2012) and General Electric Capital Canada Inc. v. Canada, [2009] T.C.J. No. 489 (Tax Court appeal)

28 Moody's Case [80-81]

${ }^{29}$ Although not addressed by the Tribunal (due to the scope of its function), the SFC may nevertheless have powers in relation to the Report qua information in the marketplace under the market misconduct provisions of the SFO. See S. Johnstone, "Credit ratings: The Moody's case", Hong Kong Law Journal 47(1) 2017, section 4.4

30 Moody's Case [102]

31 Moody's Case [29], [31], [92]

32 Moody's Case [93]

33 Moody's Case [102]
} 


\subsection{Import of the Moody's case}

The powers of the Tribunal are considerable, ${ }^{34}$ and its determinations are binding subject to a right of appeal to the Court of Appeal. A failure to comply with its orders constitutes a criminal offence. ${ }^{35}$ However, a determination by the Tribunal is technically incapable of affecting the law as a result of the nature of the Tribunal insofar as it is a statutory tribunal, not a Court of law part of the Hong Kong court system.

Nevertheless, the Tribunal is an important part of Hong Kong's regulatory architecture and system of checks and balances on the exercise of regulatory power, and a determination by the Tribunal carries significant weight. While the correctness of the Tribunal's determination has been questioned, ${ }^{36}$ and Moody's has appealed the decision, the determination does establish important boundary lines on the scope of the HK regime that guide both the industry and its regulator as to the interpretation and implementation of the CRA regime. ${ }^{37}$

Although different jurisdictions have provided for similar, though not identical, definitions of "credit rating", aligning the meaning and scope of the term is important given the sought-after consistency in the international approach to CRA regulation. The alignment of Hong Kong's statutory use of the term with international expectations, fundamental to the origins of the HK regime, is of particular relevance in view of the first condition attached to the equivalence decision noted above. Viewed from this perspective, if the effect of the Tribunal's determination was to represent a material departure from the understanding of ESMA or the European Commission, this may suggest that a generally consistent approach has not developed or been maintained in Hong Kong, possibly causing Hong Kong's continued standing as an equivalent jurisdiction to be called into question.

One might rephrase the problem more specifically: would the issue of the Report be regarded for the purposes of EU regulation as that of a credit rating agency issuing a credit rating? If the answer is no, this would appear to confirm a problematic equivalence gap exists. This conceivably could require a reassessment of Hong Kong's continued equivalence, placing a central purpose of implementing the $\mathrm{HK}$ regime at risk of failure.

\section{Assessing the determination}

The following sections of this article identify four elements central to the Tribunal's interpretation and application of the HK regime, regarding its:
information-based perimeter;
document-based perimeter;
act-based perimeter; and
primary regulatory objective;

The analysis of the Tribunal's approach to these elements suggests a departure from the origins and purposes of the international approach and, in particular,

\footnotetext{
${ }^{34}$ Including the power under section 218 (2) of the SFO to confirm, vary or set aside SFC decisions, including the disciplinary powers exercised by the SFC in the Moody's case.

${ }^{35}$ See generally SFO, Part XI, Division 2

${ }^{36}$ See S. Johnstone, "Credit ratings: The Moody's case", op. cit.

${ }^{37}$ Moody's has since appealed the Tribunal's determination and this will bring the case before the Court of Appeal (see SFO, Part XI, Division 3), a body that is able to establish legal precedent
} 
from the EU regime on which it is closely based. Two of the requirements set out in the first condition of the equivalence decision cited above will be relevant to consider, namely, the authorization requirements and/or the effective application of the supervisory arrangements.

\subsection{Information-based perimeter - what constitutes a credit rating?}

The Tribunal's determination in important ways turns on its treatment of the term "credit rating". It noted that credit ratings refer to the risk of debt not being paid when due:

" 'Credit ratings' have been described as 'opinions about relative credit risk' and 'credit risk' itself has been described as 'the potential for loss due to failure of a borrower to meet its contractual obligation to repay a debt in accordance with the agreed terms'." ${ }^{38}$

This definition, while not incorrect and useful for some purposes, glosses over distinctions between "creditworthiness" qua the assessment of credit risk, and "credit rating" which refers only to the opinion expressed on creditworthiness. The Tribunal did not undertake any detailed analysis of the term "credit rating" and regarded it as being

"broadly defined. The Legislature has not condescended to specific
accountancy directives or mathematical formulae..... It allows for different
forms of credit ratings in respect of a range of subject matters. ... [and] is
broadly drafted so as to meet the exigencies of changing circumstances ...
Understandably, therefore, the [SFO] defines 'credit ratings' as 'opinions',
that is, as views, judgments or beliefs, without any limitation to their form
other than that they are 'expressed' using a 'defined rankings system',
namely, a system that divides its subject matter into ranks or classes that
are clearly specified" 39

The following analysis suggests the Tribunal's approach to a material extent rests on a commingling of elements relevant to credit ratings that is at variance with the approach of the EU regime to the CRA industry. These elements are: (1) the connections and distinctions between credit risk, creditworthiness and the opinion expressed on creditworthiness; and (2) the relationship between methodology and a rating opinion, in particular, the relevance of a CRA's methodology to a rating opinion once it has been issued. These divergences give rise to the possibility of mismatch - that what might be regarded as a credit rating under the $\mathrm{HK}$ regime might not be regarded as one under EU regime. To better appreciate the approach taken by the Tribunal it is first necessary to consider the meaning of "credit rating" as generally understood.

\section{Definitions of credit rating}

Different jurisdictions have not adopted identical language when implementing CRA regimes owing, in part, to differences in legal systems and regulatory architectures. However, each of them are closely connected to IOSCO's definition:

\footnotetext{
${ }^{38}$ The Tribunal quoting a definition provided by the Global Association of Risk Professionals (Moody's Case [9])

39 Moody's Case [81-83]
} 
"'Credit rating'... means an assessment regarding the creditworthiness of an entity or obligation, expressed using an established and defined ranking system ${ }^{\prime 40}$

The definition in article 3, 1(a) of the EU regime follows this quite closely:

"an opinion regarding the creditworthiness of an entity, a debt or financial obligation, debt security, preferred share or other financial instrument, or of an issuer of such a debt or financial obligation, debt security, preferred share or other financial instrument, issued using an established and defined ranking system of rating categories".

United States laws provides for similar definitions. ${ }^{41}$

The statutory component of the HK regime provides that credit ratings are:

"opinions, expressed using a defined ranking system, primarily regarding the creditworthiness of- (a) a person other than an individual; (b) debt securities; (c) preferred securities; or (d) an agreement to provide credit". ${ }^{42}$

It will be noted that the Hong Kong legislation incorporates two requirements that do not appear in the other definitions above, namely, that the opinion must be "expressed using a defined ranking system" and be "primarily regarding" creditworthiness. That this language is different from the EU regulation does not of itself appear to be significant as it remains the same as when the equivalence decision was made by the European Commission.

The Tax Court of Canada provides one of the few judicial statements of relevance:

"In general, a credit rating is a credit rating agency's opinion of the general creditworthiness of an obligor, or the creditworthiness of an obligor with respect to a particular debt security or other financial obligation, based on relevant risk factors." 43

That statement is in general alignment with the definitions reviewed above.

\section{Relationship between credit ratings and creditworthiness}

In each of the foregoing definitions, a credit rating involves some form of opinion or assessment on creditworthiness being expressed. "Creditworthiness" is not defined in either the HK regime or the EU regime. It is to be distinguished from "credit rating". Credit ratings are not themselves the creditworthiness - the credit rating, being an opinion on creditworthiness, points to creditworthiness. The rating is the signifier, creditworthiness the signified. That relationship is normally confined by a set of ranked symbols or icons by which a CRA seeks to facilitate a shared or common understanding of what meaning each rating is intended to

\footnotetext{
40 IOSCO CRA Code, op cit page A-4

${ }^{41}$ Exchange Act, s 3(a)(60) provides "The term 'credit rating' means an assessment of the creditworthiness of an obligor as an entity or with respect to specific securities or money market instruments. 15 USC 78c (a)(60) provides "The term 'credit rating' means an assessment of the creditworthiness of an obligor as an entity or with respect to specific securities or money market instruments."

42 SFO, Schedule 5, Part 2

43 General Electric Capital Canada Inc. v. Canada, [2009] T.C.J. No. 489 (Tax Court appeal) at 49
} 
convey. This is not only long standing industry practice but is also required by the $\mathrm{HK}$ regime and the EU regime. ${ }^{44}$

The approach not to define "creditworthiness" is consistent with international practice $^{45}$ and suggests the word be given its ordinary meaning: the extent to which a person is considered suitable for financial credit. ${ }^{46}$ Creditworthiness thus involves a consideration of what acceptable credit risk means. The subjectivity of "acceptability" can be contrasted with other factors relevant to credit risk, such as debt-to-income ratio and collateral, which are quantifiable.

Credit risk is generally recognized as representing "the capacity and willingness of a debtor to meet its obligations when due. ${ }^{\prime 47}$ This involves elements of subjective judgment in the assessment of risk that go beyond merely evaluating the relationship between an issuer's resources and financial performance and its capacity to pay.

\section{The Report}

Applying the foregoing considerations to the Report, it is clear the red flags do cover elements relevant to credit risk assessment, for example, quality of cash flow generation and deviations in working capital. However, each flag clearly is not an opinion on creditworthiness. They operate in a simple binary manner. Either the specific criterion is met and a red flag raised, or it is not and no flag is raised. This reflects the distinction between elements that might be pertinent to forming an assessment of creditworthiness, and a rating of creditworthiness that might or might not emerge from those elements. As noted above, the Report does not on its face appear to express an opinion on or be primarily concerned with creditworthiness and the language of the report on a plain reading appears to eschew a connection between the red flag framework and creditworthiness.

\section{The Tribunal's assessment of the Report}

This analysis can now return to the two points prefaced above, which suggested the Tribunal's approach to a material extent rests on a commingling of certain elements relevant to credit ratings at variance with the approach of the EU regime.

As regards (1) above (connections and distinctions between credit risk, creditworthiness and the opinion expressed on creditworthiness), the Tribunal views the Report as constituting a credit rating precisely because it comprised a system for judging levels of credit risk. ${ }^{48}$ This effectively amounts to a view on the relationship between credit risk, creditworthiness and the opinion on creditworthiness that in some sense reverses IOSCO's definition of credit ratings into: credit ratings are assessments of credit risk that produce a defined ranking system.

\footnotetext{
44 The SFC CRA Code requires a CRA to "clearly define a given rating symbol and apply it in a consistent manner", para 54. Annex 1, Section $D(2)(c)$ of the EU regime requires the meaning of rating categories to be explained when presenting a credit rating ${ }^{45}$ Papers issued by IOSCO do not define 'creditworthiness' nor does legislation in the EU, US, Japan, Australia or Mexico. For example, see 15 USC 78c

${ }^{46}$ Oxford English Dictionary Third Edition 2013

47 Q Liiu, P Lejot and DW Arner, "Finance in Asia" (Routledge 2013) 217

${ }^{48}$ Per the Tribunal: "the red flag framework constituted a well-defined system or mechanism for judging levels of credit risk and, as such, constituted a credit rating" (Moody's Case [93])
} 
The Tribunal's position stands in contrast to the position in the EU where a credit rating essentially requires the expression of a CRA's opinion of how likely an issuer is to repay, the Commission of the European Communities having stated that when a CRA issues an opinion on creditworthiness "they assess the likelihood that an issuer will default". ${ }^{49}$ As the Report only flags elements relevant to an assessment of credit risk, it is doubtful it could be regarded as capable of amounting to a credit rating as such term is understood in the EU regime. That it is so treated under the $\mathrm{HK}$ regime represents an important potential equivalence gap that goes to a central concern of the CRA regime.

As regards (2) above (relationship between methodology and a rating opinion), the alternative view of the Tribunal is that the red flag framework comprised in the Report was relevant to Moody's methodological approach to rating ${ }^{50}$ and as such it amplifies, supplements and becomes part and parcel of Moody's ratings. ${ }^{51}$

The Tribunal's willingness to allow methodology to have an ex post facto influence on a published credit rating presents another additional equivalence gap problem. Article 10(2) and Annex I, Section D of the EU regime, which specifies the requirements on the presentation of credit rating, indicates a clear distinction is to be drawn between the rating opinion expressed and the methodology used to produce it. This reflects the generally understood meaning of a credit rating that it is comprised in, as per the Federal Court of Australia in Bathurst Regional Council v Local Government Financial Services Pty Ltd, "a system of stand alone ratings where the relevant information for an investor [is] contained in the rating itself and the accompanying definition [the CRA] assigned to the rating. ${ }^{\prime \prime 2}$ That is to say the rating system is the defined scale (of $A A A, A A$, etc) - it is not comprised in the CRA's methodology or in any allocation of markers (such as red flags) that might be relevant to the CRA's methodology. These distinctions, between the methodology, the ranking system, and the opinion expressed, also mean that once a rating has been given it "is not dependent on [the CRA's] explanation of how it reached the rating. ${ }^{\prime 53}$

\section{Non-ratings that might be regarded as credit ratings}

The approach of the Tribunal in these regards gives rise to a further point of potential variance from the EU regime. It seems possible under the Tribunal's rendering of the $\mathrm{HK}$ regime that a report issued by an information provider (whether or not a licensed CRA) could be regarded as a credit rating notwithstanding that the report lacks certain features generally ascribed to credit ratings. That creditworthiness is not the primary concern of the report appears not to be determinative, however, a discussion of factors pertaining to credit risk might be. This could lead to a grey area in which certain research reports and business analyses that are not normally regarded as credit ratings elsewhere, including the EU, might be regarded as subject to the HK regime. Persons engaging in the provision of information services might be particularly exposed and may need to consider whether they are engaging in activities covered by the $\mathrm{HK}$ regime in a way they would not need to consider if they were engaging in the same activities under the EU regime.

\footnotetext{
${ }^{49}$ Commission of the European Communities, 2005, Communication from the Commission on credit rating agencies, December 23, 2005/11990, 1-9, page 2. See also the Report On The Activities of Credit Rating Agencies, IOSCO, Statement of the Technical Committee of IOSCO, September 2003

50 Moody's Case [21]. Also refer to Moody's Case [153]

51 Moody's Case [102]

52 Bathurst Regional Council v Local Government Financial Services Pty Ltd. (No 5) [2012] FCA 1200 (Federal Court of Australia) [1465]

53 Ibid [1464]
} 
Moreover, as will be reviewed next, the Tribunal's application of the HK regime means that matters outside the four corners of a document may be considered to determine if published information constitutes, or affects previously issued, credit rating opinions. Together, this creates some uncertainty as to what will be treated as research product and what falls into the special category of credit rating.

\subsection{Document-based perimeter - what else is relevant?}

The Tribunal reached its determination not through an isolated examination of the contents of Report per se but via a review of various surrounding circumstances. Matters it considered outside the four sides of the Report included: Moody's intended purposes ${ }^{54}$ in issuing the report, the genesis of the report including Moody's internal communications, processes, and expectations, ${ }^{55}$ the subsequent effect of the report in the equity and debt markets, ${ }^{56}$ and the press release issued the day the report was issued. ${ }^{\mathbf{5 7}}$

As already noted, the process by which a credit rating is produced, including the integrity of the rating process and the role of the CRA's board and its employees in that process, is dealt with by both the HK regime and the EU regime, albeit in a different structural manner. Whereas this is dealt with in Title II of the EU regime, the HK regime deals with these matters by way of the non-statutory SFC CRA Code.

Title II and the SFC CRA Code both presume the undertaking of a credit rating activity. The language of the relevant provisions takes the existence of a credit rating (albeit one that is under production) as a starting point. For example, art $6(1)$ of the EU regime requires that a credit rating be not affected by existing or potential conflicts of interest. ${ }^{58}$ As discussed in section 3.4 below, the objective of these provisions is directed to the quality of the rating production process and as such only appears relevant to apply to the production of information that is otherwise treated under the relevant regime as a credit rating.

The language of these provisions is not designed to be determinative of whether credit rating activity is being undertaken. Nor do they contain any indication that the undertaking of these responsibilities, or the beliefs or expectations of management or employees, are relevant to the separate question of whether an item of information is a credit rating.

However, the different legal structure of the HK regime and EU regime may be relevant as regards what matters may be permissible to take into account when determining what is a credit rating. The EU regime deals with both the definition of a credit rating and matters related to its production and issuance in a single piece of regulation. ${ }^{59}$ In contrast, the statutory component of the HK regime is only concerned with what a credit rating is and the fact of its issuance - the details of how it has been produced is handled by the non-statutory provisions of the SFC CRA Code, which do not bind statutory interpretation. This distinction leaves open a technical possibility that the Hong Kong statute could be subject to interpretation in way that might be subject to different considerations in the EU

\footnotetext{
54 Moody's Case $[19,21,66,93,100-101,152,102,130,147,193,214]$

55 Moody's Case [124 to 133]

56 Moody's Case [3, 18, 29, 37, 42, 193, 214]

57 The press release can be found here (last accessed May 2016)

https://www.moodys.com/research/Moodys-Accounting-and-governance-warning-signs-

for-emerging-market-companies--PR_222323

58 EU regime, art 6(1)

${ }^{59}$ In Title I and Title II respectively
} 
regime where both matters are constrained by the same piece of regulation. Certainly, the Tribunal has regarded aspects of the production process of the Report, such as intent, as relevant to the scope of application of the statutory component of the $\mathrm{HK}$ regime. In this regard it is notable that the Tribunal when interpreting the scope of the HK regime did not find the need to consider the nonstatutory SFC CRA Code - under the EU regime it would be difficult to ignore the provisions of Title II when considering Title I.

Intent plays a very specific role under both the EU regime ${ }^{60}$ and the statutory part of the $\mathrm{HK}$ regime. ${ }^{61}$ In both, the question of intent prima facie appears to apply only to the intended scope of issuance of information that constitutes a credit rating. It is clear from the language of the EU regime that intent in this regard is directed at carving out reports that are not intended for public consumption, and this is also reflected in the exemptions provided in the statutory component of the HK regime. However, the Tribunal considers intent as being relevant beyond the mere question of issuance and indeed relevant to the nature of the information itself qua credit rating. That approach does not rule out, and possibly has the unintended implication, that a Type 10 licensed person (or perhaps any person) might in fact be regarded as subject to the HK regime if they intended to prepare for issue a credit rating even if what was prepared and issued was not in fact a credit rating. This seems not possible within the EU regime.

The statutory wording that defines the HK regime also has not prevented the Tribunal from considering the effect of the Report on the price of equity and debt securities issued by companies the subject of the report, or commentary on the report by intermediaries and the media. Market reaction appears to be regarded by the Tribunal as evidence relevant to determining the nature of the Report. Nowhere in the EU regime do such considerations appear to be of any relevance.

The Tribunal also cites the press release Moody's issued the day the Report was published as relevant to an understanding of "the nature and purpose ${ }^{\prime 62}$ of the Report. It forms part of the means by which the Tribunal considered Moody's to have engaged in Type 10 regulated activity when it issued the Report because it regarded the press release as conditioning readers in such a way as to influence their reading and understanding of the Report. While this appears to arise from the Tribunal's purposive approach to legislative interpretation, it represents an expansion of what documentary material is relevant to consider for the purposes of defining the scope of the HK regime. It might also be pointed out that this would have consequences as to the understanding of what is a credit rating (discussed in section 3.1 above) since it would seem to allow that a rating opinion may be spread across more than a single document.

The EU regime does contemplate the role of press releases and other reports CRAs are required to issue them to explain the key elements underlying a credit rating that is being announced. ${ }^{63}$ The HK regime also provides for this, ${ }^{64}$ however, as the requirement is only contained in non-statutory regulations, for the reasons explained above this gives technical leeway for legislative interpretation in Hong Kong that may be constrained in the EU. Indeed, the Tribunal's application of the $\mathrm{HK}$ regime gives a role to the press release that might be difficult to reach under the EU regime.

\footnotetext{
${ }^{60}$ EU regime, art 2(2)(a), Recital (19)

${ }^{61}$ Definition of "providing credit rating services" in SFO, Schedule 5, Part 2

62 Moody's Case [19]

${ }^{63}$ EU regime, Annex I, Section D, para 5

${ }^{64}$ SFC CRA Code, para 55
} 
A plain reading of the language in the EU regime, including its recitals, does not indicate that extrinsic factors such as those considered by the Tribunal are relevant to the nature of a report for the purposes of determining whether it is subject to the EU regime. In the absence of any EU ruling, it is not possible to state with certainty whether the EU regime is intended to encompass such extrinsic factors. However, it is notable that important foundations of the EU regime, such as the IOSCO CRA Principles and the IOSCO CRA Code, do not make any reference to extrinsic factors being of any relevance in these regards.

As already noted, although the language and structure of the HK regime is not identical to the EU regime, it is nevertheless sufficiently the same for the purposes of the equivalence decision. However, it is certainly possible that subsequent interpretations or applications of the HK regime may result in discrepancies arising between the two regimes. Indeed, IOSCO has noted that discrepancies between different CRA regimes may arise as they are implemented and applied. ${ }^{65}$

\subsection{Act-based perimeter - what acts are regulated?}

As noted in section 2.3 above, the Tribunal took as its primary focus the regulated activity of providing credit rating services as it regarded the phrase "credit rating" as being broadly defined. That focus meant the Tribunal was also concerned to establish what acts of a CRA should fall within the HK regime and so be subjected to the SFC's regulatory oversight. In doing so, the Tribunal was effectively determining an important act-based perimeter of the HK regime. The following analysis suggests that the approach of the Tribunal is possibly wider than what is contemplated by the EU regime.

The primary constraint around the definition of Type 10 regulated activity appears to be that a credit rating must be prepared for dissemination or distribution. By implication, it would appear not to be the case that all activities of Type 10 licensed persons are regulated - only the activities of CRAs that concern the credit ratings it prepares for dissemination or distribution are. This seems consistent with the objectives of the CRA regime as understood internationally. ${ }^{66}$

However, the Tribunal when considering this issue took an approach that was based not on the HK regime per se but was instead based on the SFC's statutory powers to discipline regulated intermediaries, which includes licensed CRAs. Section 194 of the SFO empowers the SFC to impose discipline where a regulated intermediary has engaged in misconduct, which includes any

"act or omission relating to the carrying on of any regulated activity ... which, in the opinion of the [SFC], is or is likely to be prejudicial to the interest of the investing public or to the public interest" (emphasis added). ${ }^{67}$

The Tribunal regarded the phrase as having a broad meaning ${ }^{68}$ and, since the Tribunal's position was that the Report is connected to Moody's existing ratings, the Tribunal was of the view that the act of publishing the Report was an act relating to those earlier ratings. ${ }^{69}$ While the Tribunal did not provide further

\footnotetext{
65 IOSCO CRA Principles, page 38

66 See section 1 above

67 SFO, s 193(1)(d)

68 Moody's Case [106]

69 Moody's Case [106]
} 
guidance on the scope of the phrase "relating to", it is nevertheless clear that the Tribunal's approach captures a wider group of acts than those contemplated by the SFC CRA Code, not least because the matters relevant to the Tribunal's determination are not addressed by that code. ${ }^{70}$ This is notable because the SFC CRA Code, which was central to implementing the HK regime to address acts involved in the credit rating process, is closely and purposely aligned with the EU regime - there is a high degree of conformity of the provisions of the SFC CRA Code to the EU regime. ${ }^{71}$

This suggests that the effective scope of the HK regime, when understood through the lens of other applicable provisions of Hong Kong's regulatory architecture, may be wider than the EU regime. This seems unproblematic as regards the equivalence decision insofar as acts of CRAs regulated in the EU would nevertheless appear to remain regulated in Hong Kong.

However, a wider regime also implies that some acts of CRAs subject to regulatory oversight in Hong Kong would not be regarded as subject to the EU regime if the same acts were undertaken in the EU. While this may cover a range of acts, a specific example of this discrepancy may be ancillary services.

Both the EU regime and the HK regime contemplate ancillary services being undertaken by regulated CRAs. ${ }^{72}$ The EU regime specifically excludes them from being part of credit rating activities. ${ }^{73}$ The EU regime provides that ancillary services "comprise market forecasts, estimates of economic trends, pricing analysis and other general data analysis as well as related distribution services" ${ }^{74}$ In the United States, ancillary services means "products and services other than credit ratings". ${ }^{75}$ The HK regime is silent as to the scope of ancillary services.

The EU regime expressly recognizes that credit rating agencies should also be able to perform ancillary activities provided only that it does not create conflicts of interest or independence concerns. ${ }^{76}$ Accordingly, ancillary services would only become relevant to consider if they create concerns about the integrity of the rating. While that is also the case in Hong Kong, the Tribunal's determination in effect means there is an additional circumstance where an ancillary service may be relevant to, and indeed would become subject to, the HK regime, namely, if the ancillary service is construed as "relating to" credit rating services. Given the broad meaning attributed to that phrase by the Tribunal, the scope of this could be difficult to specify.

To the extent this differs from the imperative and permissive language in the EU this may in effect restrain the EU concept insofar as the HK regime may subject some ancillary services to regulatory oversight in a manner that the EU regime would not. This could potentially represent an equivalence gap on the basis that article 6 of the EU regime requires that an equivalence decision is premised on the requirements of the third jurisdiction being "equivalent to the requirements resulting from" the EU regime. ESMA's technical advice that the HK regime was

\footnotetext{
70 The SFC General Code was relevant to the Tribunal's determination, however, that code applies to all persons licensed or registered by the SFC and is not specific to CRAs

71 In particular, Title II of the EU regime

72 EU regime, Annex I, Section B, para 4, and SFC CRA Code, para 30

${ }^{73}$ EU regime, Annex I, Section B, para 4

${ }^{74} \mathrm{EU}$ regime, Annex I, Section $B$, para 4

75 SEC, 17 CFR Parts 232, 240, 249, and 249b, Release No. 34-72936; File No. S7-18-11, RIN 3235-AL15, page 24

${ }^{76}$ EU regime, Recital (6); see also EU regime, Recital (22) and Annex I, Section B, para 4
} 
comparable to the EU regime "in its outcomes"77 might not still be the case when considering a CRA's other activities and the requirements they are subject to when performing them in Hong Kong.

The lack of a clear perimeter between which acts of a CRA are regarded as "relating to" its credit rating services and so subject to regulatory oversight, and which are not are a source of further concern. Although the line between regulated and non-regulated acts should be a fundamental one to draw, this appears to be uncertain under the Tribunal's rendering of the HK regime given the absence of regulatory guidance on the matter. This could raise doubt over whether the HK regime remains such that the powers of regulators and responsible authorities can be exercised in a transparent, fair and equitable manner, as required by Principle 6.5 of IOSCO's "Objectives and principles of securities regulation". ${ }^{78}$ If so, it may become necessary to consider whether the supervisory requirements of the HK regime can be "effectively applied", as required by the first condition of the equivalence decision.

\subsection{Regulatory objective - what is the primary purpose?}

When implementing CRA regulatory oversight, the approach internationally has been to use regulatory definitions that build on each other, namely, a definition of "credit rating" and a definition of "credit rating agency". Different jurisdictions have implemented CRA regulation in a way that fits into their own legal and regulatory architecture but nevertheless achieves sufficient consistency with the approach internationally. This includes Argentina, Australia, Brazil, the EU, Hong Kong, Japan, Mexico, Singapore, and the United States. ${ }^{79}$. In Hong Kong, the means by which credit ratings were brought under regulatory oversight was via the statutory creation of Type 10 regulatory activity. ${ }^{80}$

The analysis in this section suggests that the primary concern of CRA regulation internationally is the quality of credit ratings and that the Tribunal's primary focus on Type 10 regulated activity in effect causes the originating objectives of CRA regulation to be viewed from the wrong end of the telescope, resulting in consequential discrepancies from the approach in the EU regime.

A different starting point from the one taken by the Tribunal might have been to undertake a close examination of the statutorily defined term "credit rating" and apply it to the Report to determine if its issuance constituted the provision of a credit rating service. This reflects the hierarchy of terms defined by the SFO, which provides that Type 10 regulated activity comprises "preparing credit ratings... for dissemination to the public... or... for distribution by subscription". ${ }^{81}$ Credit rating services would therefore only seem capable of being undertaken in respect of reports that are credit ratings. Accordingly, the first matter that would seem to require consideration is whether an item of information is or is not a credit rating - only if it is would it seem relevant to consider the requirements attaching to Type 10 regulated activity.

Beginning with a consideration of whether the nature of information amounts to a credit rating is consistent with the international context being primarily concerned

\footnotetext{
77 Equivalence decision, Recital (2), Official Journal of the European Union, vol 57, 3 May 2014, page 76

78 May 2003

79 See IOSCO CRA Principles, page 38; Official Journal of the European Union, Volume 573 May 2014

${ }^{80}$ An approach similar to the NRSRO system in the U.S. in which CRAs are recognized by the relevant authorities - see Arner et al, op cit 369

${ }^{81}$ SFO, Schedule 5, Part 2
} 
with the quality of credit ratings. The means by which the G20 envisaged the "transparency and quality of the rating process" would be safeguarded was via "a regulatory oversight regime that includes registration" consistent with the IOSCO CRA Code. ${ }^{82}$ The IOSCO CRA Code is based on the four principles set out in the IOSCO CRA Principles, three of which also take as their primary concern the credit rating:

the first principle, quality and integrity in the rating process, takes as its objective that opinions should help reduce information asymmetries;

the second principle is that rating decisions should be independent and free from conflicts of interest;

the third principle is that ratings activities should be timely and transparent. ${ }^{83}$

The recitals to the EU regime also confirm the objective of the regulation is to ensure that credit ratings used in the Community are "independent, objective and of adequate quality" ${ }^{\prime 84}$ and to lay down a common framework addressing the quality of credit ratings. ${ }^{85}$ Article 1 of the EU regime indicates that regulatory oversight of CRAs is merely the means of enhancing the reliability and quality of credit ratings issued in the Community and that important means of doing to are to enhance the integrity, transparency, responsibility and good governance of CRAs including through independence and the avoidance of conflicts of interest. This notably does not take as its primary concern the activities of CRAs per se, but only to those comprised in the analysis, evaluation, approval, issuing and review of credit ratings. ${ }^{86}$ In brief, CRA conduct only appears to be relevant insofar as it concerns the quality of the credit ratings a CRA issues.

\section{Conclusions}

The foregoing analysis of the Tribunal's determination has suggested the Tribunal's interpretation and application of the HK regime may be at variance with the EU regime along four main axes: the information, documentary and act based perimeters of the CRA regime as well as its primary regulatory objective. The regulatory objective may have shifted such that there is a different emphasis on the acts of CRAs. Closely connected to the foregoing, the requirements for information to be treated as a credit rating appear to have become broader and less specific. This includes the range of matters that can be taken into account in determining the nature, or effect, of information that may be credit-related. The range of acts undertaken by CRAs that are subject to the HK regime appears to be wider, and less certain in scope.

The Tribunal's standing in Hong Kong's regulatory architecture requires that the regulator and the industry be guided by its determination accordingly. In practice, this means that a certain matters could be treated as falling within the HK regime when they would not be so treated in the EU, for example: an item of information being treated as a credit rating; an item of methodological information being regarded as affecting a credit rating that has previously been issued; an act of a CRA being treated as part of its regulated CRA activities.

\footnotetext{
${ }^{82}$ G20 Declaration, op cit

${ }^{83}$ Emphasis added. The fourth principle is concerned with the handling of confidential information

84 EU regime, Recital (1)

${ }^{85}$ EU regime, Recital (75)

${ }^{86}$ EU regime, art 3(1)(0)
} 
Given these examples are not minor variances but strike at central concerns of CRA regulation, this suggests an equivalence gap may have opened up which could raise concerns over Hong Kong's continued status as an equivalent jurisdiction. The present hiatus in this regard is that Moody's has appealed the Tribunal's determination to the Court of Appeal. The appeal allows the Court to review the determination and to correct any failure or mistake the Tribunal has made. A relevant factor for the Court of Appeal to consider will be the purposes of introducing the $\mathrm{HK}$ regime and an important factor in this regard is that the design and implementation of the HK regime was to ensure that it would meet the EU's test of equivalence and/or stringency so that credit ratings issued by CRAs based in Hong Kong are serviceable in the EU. The analysis in this paper therefore suggests the Court of Appeal may need to consider whether aspects of the Tribunal's approach, if upheld, could place Hong Kong's status as an equivalent jurisdiction in doubt. Unlike the Tribunal's determination, the Court's ruling will establish law. A binding Court ruling that supports any equivalence gap implicit in the Tribunal's determination may be a matter the European Commission is obliged to consider.

The problem is not exclusively related to the EU context. The introduction of CRA regulation globally has been part of an international effort that seeks to provide a uniform approach to CRA regulatory oversight. IOSCO has noted that as CRA regulatory programs are implemented, it will be important for supervisors to keep under review the effectiveness of those programs, in particular, whether the program gives rise to cross-border conflicts for CRAs. ${ }^{87}$ To the extent such a conflict between regimes exists, Hong Kong regulators and policymakers should note that IOSCO requires that they "seek timely and reasonable accommodations so long as the IOSCO principles are not compromised. ${ }^{188}$

${ }^{87}$ IOSCO, FR04/11 February 2011, page 38 op cit
${ }^{88}$ Ibid. 